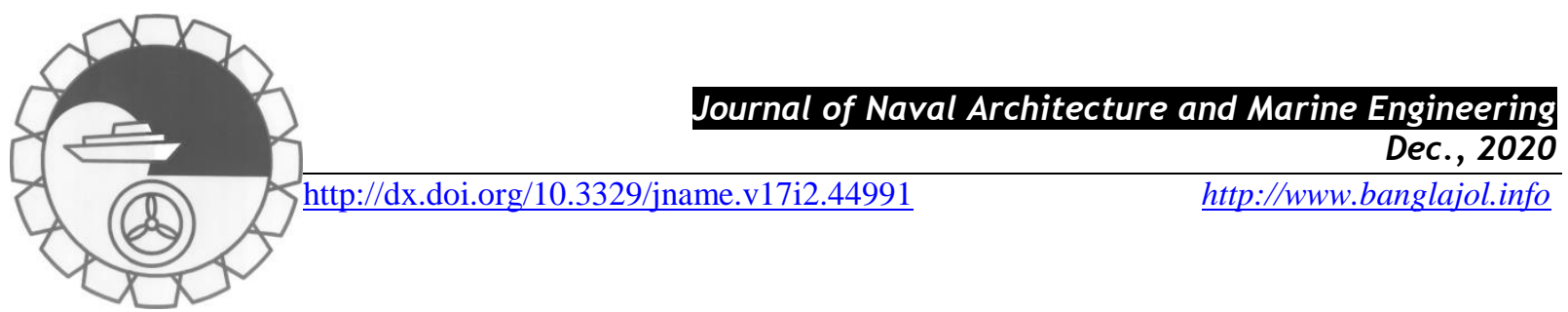

\title{
ENHANCEMENT OF NATURAL CONVECTION HEAT TRANSFER IN CONCENTRIC ANNULAR SPACE USING INCLINED ELLIPTICAL CYLINDER
}

\section{H. Laidoudi ${ }^{1}$, M. Helmaoui ${ }^{1}$}

${ }^{1}$ Laboratory of Sciences and Marine Engineering (LSIM), Faculty of Mechanical engineering, USTO-MB, BP 1505, El-Menaouer, Oran 31000, Algeria

*Email: houssem.laidoudi@univ-usto.dz

\begin{abstract}
:
The governing equations of continuity, momentum and energy are numerically solved to study the laminar natural convection heat transfer of Newtonian fluid confined within two concentric cylinders. The inner cylinder is elliptical cross-section with different aspect ratio $E=0.1$ to 0.5 and it is considered to be hot, whereas the outer cylinder is circular and it is supposed to be cold. The annular spacing between the cylinders is defined based on radii ratio $(R R=2.5)$. Also, the inner cylinder is inclined with an inclination angle $(\theta=0$ to 90$)$. The main purpose of this study is to determine the effects of inclination angle $\left(\theta=0^{\circ}\right.$ to $\left.90^{\circ}\right)$, aspect ratio of inner cylinder $(E=0.1$ to 0.5$)$, Prandtl number $\left(\mathrm{Pr}=0.71\right.$ and 7.01) and Rayleigh number $\left(\mathrm{Ra}=10^{3}\right.$ to $\left.10^{5}\right)$ on fluid flow and heat transfer rate. The flow patterns and temperature distributions are potted in terms of streamlines and isotherms, respectively. The obtained results showed that increase in inclination angle enhances the heat transfer rate of inner cylinder for all values of aspect ratio for example for $E=0.1, \operatorname{Pr}=0.71$ and $R a=10^{5}$ increase $\theta$ from $0^{\circ}$ to $90^{\circ}$ increases the $\mathrm{Nu}$ by $24.23 \%$. Also, for the inclination angle $\left(\theta=90^{\circ}\right)$, the decrease in aspect ratio $(E)$ improves the heat transfer rate of inner cylinder.
\end{abstract}

Keywords: Natural convection, laminar flow, steady simulation, heat transfer, elliptical annuli, inclination angle.

\section{NOMENCLATURE}

a big elliptical radius [m]

$b \quad$ small elliptical radius [m]

E aspect ratio [-]

$g$ gravity acceleration $\left[\mathrm{ms}^{-2}\right]$

$L \quad$ annular spacing length [m]

$n_{s} \quad$ normal direction [-]

$\mathrm{Nu}_{l} \quad$ average Nusselt number [-]

$\mathrm{Nu} \quad$ local Nusselt number [-]

$p \quad$ pressure $[\mathrm{Pa}]$

$\mathrm{Pr} \quad$ Prandtl number [-]

$r \quad$ radius of outer cylinder [m]

$R R \quad$ radii ratio [-]

$R a \quad$ Rayleigh number, [-]

$T$ temperature [K]

$$
\begin{array}{ll}
T_{c} & \text { cold temperature }[\mathrm{K}] \\
T_{h} & \text { hot temperature }[\mathrm{K}] \\
u & \text { axial velocity }[\mathrm{m} / \mathrm{s}] \\
v & \text { radial velocity }[\mathrm{m} / \mathrm{s}] \\
x & \text { axial coordinate }[\mathrm{m}] \\
y & \text { radial coordinate }[\mathrm{m}]
\end{array}
$$

\section{Greek symbols}

$\alpha \quad$ thermal diffusivity $\left[\mathrm{m}^{2} / \mathrm{s}\right]$

$\beta \quad$ coefficient of volume expansion $\left[\mathrm{K}^{-1}\right]$

$v \quad$ kinematic viscosity $\left[\mathrm{m}^{2} / \mathrm{s}\right]$

$\rho \quad$ density of fluid $\left[\mathrm{kg} / \mathrm{m}^{3}\right]$

$\theta \quad$ inclination angle [degrees]

\section{Superscripts}

* dimensionless quantity

\section{Introduction}

Laminar natural convection heat transfer inside an annular enclosure occurs in many fields of industrial applications such as solar collectors as a first category, heat exchangers, refrigeration systems, applications of food treatment, electronic cooling systems and so on. Physically, in natural convection mechanism, the heated 
surfaces of an object are principally the source of fluid motion based on the concept of Boussinesq approximation. Therefore, it is important to understand correctly the behavior of this mechanism before designing such systems. Furthermore, the new concept of modern technology in electronic industries emphasizes on increasing the power of electronic elements while decreasing the physical size of the elements. As a result, the electronic elements generate more thermal energy and the efficient cooling systems are also needed to evacuate this generated energy. The previous studies on natural convection in cylindrical annulus showed that the thermal performance of annulus depends mainly on two kinds of parameters which are the geometrical configuration and the thermo-physical characteristics of the fluid by Zhang et al. (1992), Yoo and Han (2000) and Wei and Tao (1996). Many researchers studied numerically and experimentally the effects thermal buoyancy on fluid patterns and heat transfer between two horizontal cylinders of circular cross-section such as: Sheremet and Pop (2015), Nasiri et al. (2016), Choi and Choi (2017), Lamacz et al. (2011), Kuehn and Goldstein (1976), Char and Lee (1998) and Kumar (1988).

The main purpose of those works is to understanding the effects of Prandtl number, Rayleigh number, the annular spacing and the nature of fluid on the global fluid flow and heat transfer rate. From those researches, it was concluded that increase in Prandtl and Rayleigh numbers increases the heat transfer rates. Also, the eccentricity of inner cylinder is a principal factor that can enhance the heat transfer of inner cylinder. Some researchers tried to increase the heat transfer of inner cylinder by adding fins to inner cylinder as done by Arbaban and Salimpour (2015). It was found that the number and the position of fins enhance the heat transfer rate. Nada and Said (2019) numerically studied the natural convection heat transfer in annular space of two concentric circular cylinders. The inner cylinder contains a number of fins. The results showed that the number of fins have a tendency to increase the heat transfer rate. Matin and Khan (2013) exploited the effects of rheological behavior of power-law fluids to enhance the heat transfer rate of inner circular cylinder. It was also found that the effect of Prandtl number on fluid flow and heat transfer is almost negligible when $\operatorname{Pr}>10$. AbuNada et al. (2008) numerically investigated the natural convection between two concentric annuls of circular cross-sectional shape. The results showed that the usage of nanofluids increases the heat transfer rate of inner cylinder. There are also some researchers tried to enhance the natural convection heat transfer of inner cylinder by using different cross-sectional shape of inner cylinder. Tayebi et al. (2017) used the confocal elliptical cylinders for annulus. Kefayati and Tang (2018) studied the natural convection heat transfer inside square cavity containing obstacle of different cross-sections (circular and elliptical). The studied fluid for this research is viscoplastic. The study tested the effects of cross-sectional shape of cylinder, Rayleigh number and inclination angle of cylinder on fluid flow and heat transfer rate. The results showed that all these governing parameters have a significant effect on heat transfer rate and fluid flow. Eldesouki (2011) carried out an experimental work on free convection between two elliptical cylinders. The results showed that the eccentricity arrangement of inner cylinder enhances the heat transfer rate. Furthermore, series of new researches are well done to study the buoyancy-driven flow in the annular spaces under different situations such as: Laidoudi (2020a), Laidoudi et al. (2020), Mebarek-Oudina (2017), Laidoudi and Ameur (2020), Laidoudi (2020b), Mebarek-Oudina (2018), Ahmed et al.(2018), Mebarek-Oudina and Bessaih (2019).

Based on brief literature survey, it can be concluded that there are many scientific researches in the field of natural convection heat transfer between two horizontal cylinders but a few of them treated the elliptical crosssectional shape of inner cylinder. Therefore, the main purpose of this work is to investigate the natural convection heat transfer and fluid flow between two horizontal cylinders. The inner cylinder is elliptical with different aspect ratio $(E=0.1$ to 0.5$)$ and it is subjected to inclination angle $\left(\theta=0^{\circ}\right.$ to $\left.90^{\circ}\right)$. On other hand, the outer cylinder is kept circular. The natural convection heat transfer for present configuration geometries is studied for these range of governing parameters $\operatorname{Ra}=10^{3}$ to $10^{5}$ and $\operatorname{Pr}=0.71$ to 7.01 . Moreover, the present investigation is a continuation of our previous works.

\section{Physical Description, Governing Equations and Boundary Conditions}

Figure 1 is the incarnation of present physical model with suitable mesh. It is a two-dimensional cylindrical annulus of different cross-sections in Cartesian coordinate system. The physical model consists of two horizontal concentric cylinders, the inner cylinder is elliptical with aspect ratio $(E=b / a=0.1,0.25,0.4$ and 0.5$)$. The length $(a)$ of inner cylinder to the diameter $(r)$ of outer cylinder gives the radii ratio $(R R=2.5)$. The maximum gap spacing between cylinders is given by $L=r-a$. Furthermore, the inner cylinder is subjected to an inclination angle $\left(\theta=0^{\circ}\right.$ to $\left.90^{\circ}\right)$. The surface of inner cylinder is assumed to be hot $\left(T_{h}\right)$, whereas the outer cylinder surface is supposed to be cold $\left(T_{c}\right)$. 


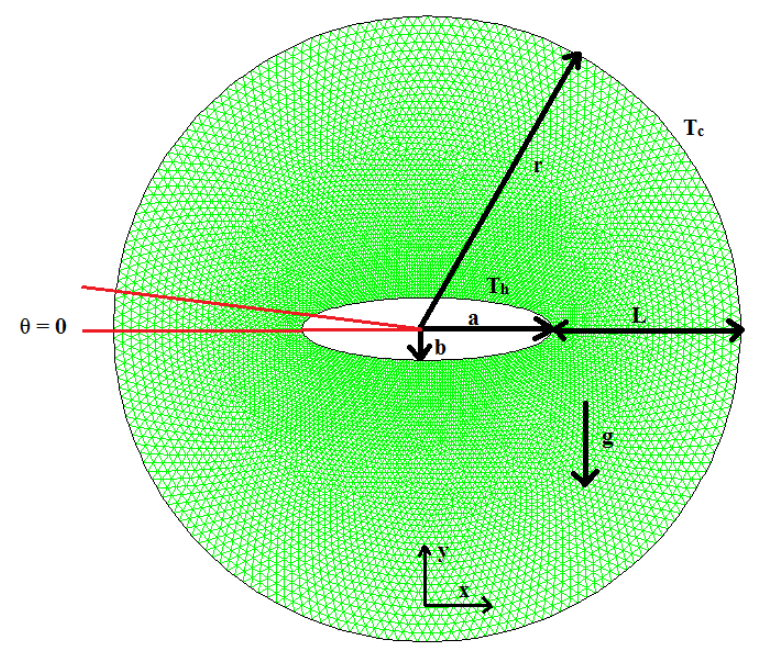

Figure 1: Geometrical illustration of present problem with generated mesh.

For present study, the thermo-physical proprieties of the fluid are assumed to be constant and they are not depended on temperature, expect for the density which is treated by following the Boussinesq approximation. The governing equations describing the natural convection heat transfer in annular space and for steady-state simulations (Laidoudi (2020c)) are written in two-dimensionless forms as:

$$
\begin{aligned}
& \frac{\partial u^{*}}{\partial x^{*}}+\frac{\partial v^{*}}{\partial y^{*}}=0 \\
& u^{*} \frac{\partial u^{*}}{\partial x^{*}}+v^{*} \frac{\partial u^{*}}{\partial y^{*}}=-\frac{\partial p^{*}}{\partial x^{*}}+\operatorname{Pr}\left(\frac{\partial^{2} u^{*}}{\partial x^{* 2}}+\frac{\partial^{2} u^{*}}{\partial y^{* 2}}\right), \\
& u^{*} \frac{\partial v^{*}}{\partial x^{*}}+v^{*} \frac{\partial v^{*}}{\partial y^{*}}=-\frac{\partial p^{*}}{\partial y^{*}}+\operatorname{Pr}\left(\frac{\partial^{2} v^{*}}{\partial x^{* 2}}+\frac{\partial^{2} v^{*}}{\partial y^{* 2}}\right)+R a \cdot \operatorname{Pr} \cdot T^{*}, \\
& u^{*} \frac{\partial T^{*}}{\partial x^{*}}+v^{*} \frac{\partial T^{*}}{\partial y^{*}}=\left(\frac{\partial^{2} T^{*}}{\partial x^{* 2}}+\frac{\partial^{2} T^{*}}{\partial y^{* 2}}\right)
\end{aligned}
$$

where $u^{*}, v^{*}, p^{*}, T^{*}, R a, \operatorname{Pr}$ are the flow dimensionless velocity along $x^{*}, y^{*}$ directions, dimensionless pressure, dimensionless temperature, Rayleigh number and Prandtl number respectively. The dimensionless variables are determined from their dimensional quantities as:

$$
\begin{aligned}
& x^{*}=\frac{x}{L}, y^{*}=\frac{y}{L}, u^{*}=\frac{u L}{\alpha}, u^{*}=\frac{u L}{\alpha}, v^{*}=\frac{v L}{\alpha}, p^{*}=\frac{p L^{2}}{\rho \alpha^{2}}, T^{*}=\frac{T-T_{c}}{T_{h}-T_{c}}, \\
& \operatorname{Ra}=\frac{g \beta\left(T_{h}-T_{c}\right) L^{3}}{v \alpha}, \operatorname{Pr}=\frac{v}{\alpha} .
\end{aligned}
$$

The characteristics of the fluid used for present investigation are given by the density $\rho$, kinematic viscosity $v$, thermal diffusivity $\alpha$ and expansion coefficient $\beta$. The acceleration gravitation is $g$.

The quantitative value of heat transfer rate of inner cylinder is calculated under the dimensionless value of average Nusselt number. The average Nusselt number is given by the expression:

$$
N u=\int_{0}^{2 \pi} N u_{l} d \theta .
$$


The local Nussel $\left(N u_{l}\right)$ along the surface of inner cylinder is defined as:

$N u_{l}=-\frac{\partial T^{*}}{\partial n_{s}}$.

where $n_{s}$ is the direction normal to wall surface of the cylinder.

The above equations are subjected to suitable boundary conditions as follows:

The values of dimensionless velocities and temperature on inner and outer cylinder surfaces are given by following values respectively:

$u^{*}=0, v^{*}=0, T^{*}=1$, for the elliptical cylinder.

$u^{*}=0, v^{*}=0, T^{*}=0$, for the outer cold cylinder.

\section{Computational Methodology}

The governing equations of continuity, momentum and energy subjected to aforementioned boundary conditions are solved numerically using the finite-volume method. The governing partial equations are descretizing into a system of algebraic equations. The convective terms of the algebraic equations are descretized using High resolution discretization scheme. For pressure-velocity coupling schema, SIMPLEC (Semi-Implicit Method for Pressure-Linked Equations-Consistent) algorithm is used for present methodology. The results are satisfactory considered when convergence criteria based on relative error of iterations is less than $10^{-8}$ for continuity and momentum equations and $10^{-6}$ for energy equation. Figure 1 shows also the type of grid meshing using for present computational domain. Indeed, they are unstructured triangular cellular elements of non-uniform grid spacing. Before starting the computational simulations, it is necessary to proof the satisfaction of the grid elements for considering computational domain.

Table 1 summarizes the grid independency test for the four geometries with respect to the aspect ratio $(E=0.1$, $0.25,0.4$ and 0.5 ). Four different meshes are generated for one value of aspect ratio. The average Nusselt number is calculated for each case at $\operatorname{Ra}=10^{4}, \operatorname{Pr}=7.01$ and inclination angle $\left(\theta=0^{\circ}\right)$. It can be concluded that the Mesh3 is satisfactory for all considered configurations.

Table 1: Study of grid independency mesh for $\operatorname{Ra}=10^{4}$ and $\operatorname{Pr}=7.01$.

\begin{tabular}{|c|l|l|l|l|}
\hline & Mesh1 & Mesh2 & Mesh3 & Mesh4 \\
\hline Elements for $E=0.1$ & 17,430 & 28,330 & 66,540 & 190,190 \\
\hline$N u$ & 4.5645 & 4.49198 & 4.40198 & 4.4143 \\
\hline \hline Elements for $E=0.25$ & 14,340 & 25,120 & 60,100 & 170,410 \\
\hline$N u$ & 4.2385 & 4.3454 & 4.31409 & 4.3971 \\
\hline \hline Elements for $E=0.4$ & 11,200 & 21,700 & 55,100 & 150,440 \\
\hline$N u$ & 4.1413 & 4.1594 & 4.152 & 4.1497 \\
\hline \hline Elements for $\mathrm{E}=0.5$ & 10,800 & 20,500 & 51,500 & 148,240 \\
\hline$N u$ & 4.1279 & 4.0356 & 4.02917 & 4.0232 \\
\hline
\end{tabular}

\section{Validation of Numerical Methodology}

In order to check the accuracy of present numerical methodology, we have compared the present obtained results with prier experimental results of Kuehn and Goldstein (1976), numerical results of Abu-Nada et al. (2008) and Matin and Khan (2013) for circular annulus of radii ratio 2.6 and 2.5 respectively. The results are shown in term of average Nusselt number of inner cylinder versus Rayleigh number as it is represented in Figure 2. The figure indicates a good agreement between all results. 

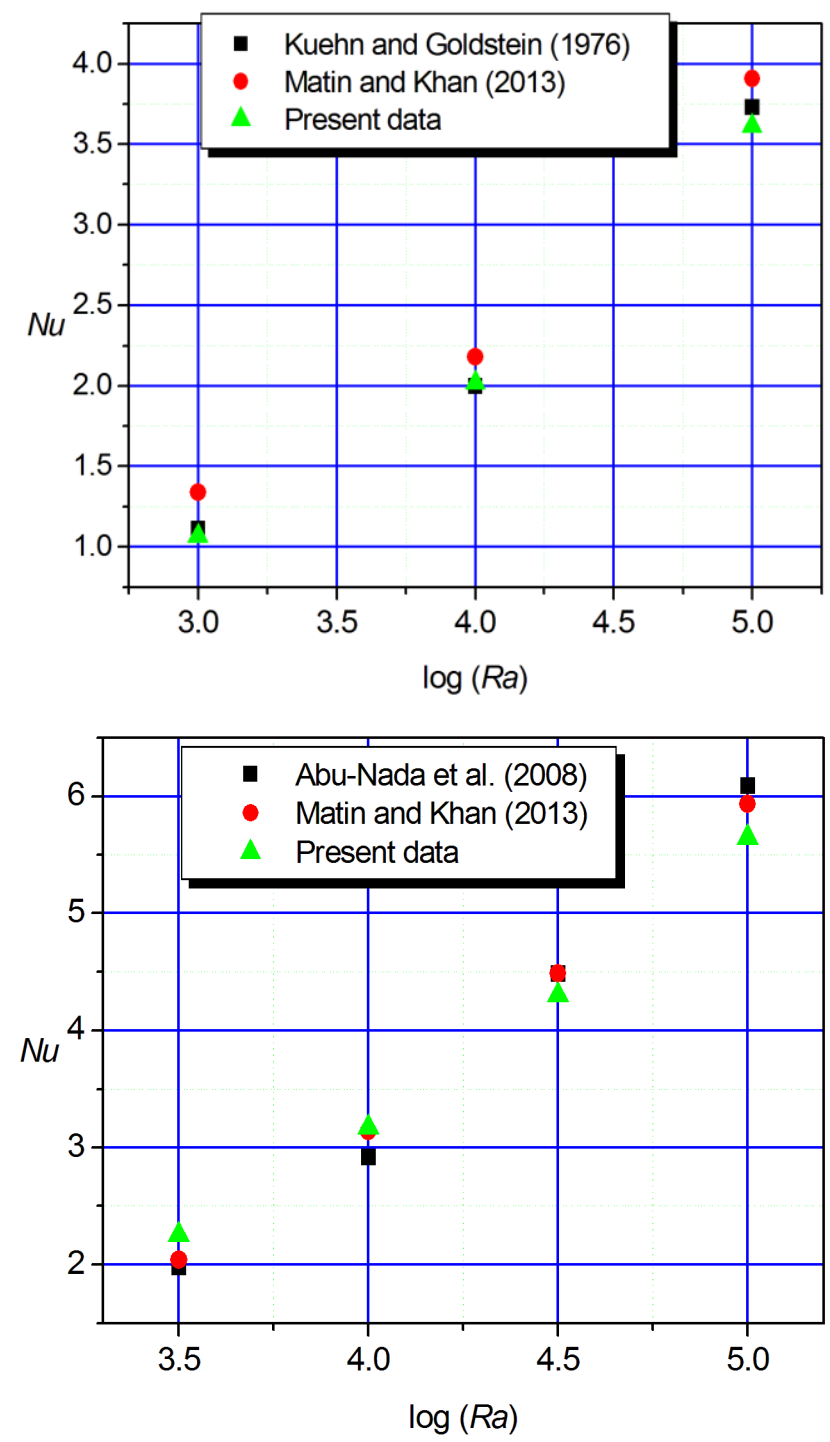

Figure 2: Comparison of average Nusselt number versus Rayleigh number at $\operatorname{Pr}=0.7$ and for $R R=2.6$ and 2.5 respectively

\section{Results and Discussion}

The effects of aspect ratio $(E=0.1,0.25,0.4$ and 0.5$)$, inclination angle $\left(\theta=0^{\circ}, 15^{\circ}, 30^{\circ}, 45^{\circ}, 60^{\circ}, 75^{\circ}\right.$ and $\left.90^{\circ}\right)$, Rayleigh number $\left(R a=10^{3}, 10^{4}\right.$ and $\left.10^{5}\right)$ and Prandtl number $(\operatorname{Pr}=0.71$ and 7.01) on fluid flow and thermal patterns are presented in potted streamline and isotherm contours respectively, this section represents also the effects of these governing parameters on the mean average Nusselt number which integrated along the surface of inner cylinder.

\subsection{Streamline contours}

Figures 3 and 4 depict the representative contours of streamline between the two cylinders for different values of aspect ratio, inclination angle and Rayleigh number at fixed value of $\operatorname{Pr}=0.71$. It can be observed that a symmetrical geometry (as: $\theta=0^{\circ}$ and $90^{\circ}$ ) generates a symmetrical streamlines but the inclined elliptical cylinder generates an asymmetrical flow patterns. For representative Rayleigh number $R a=10^{3}$ and $10^{4}$, the effect of thermal buoyancy due to temperature difference between cylinders creates a closed steady counterrotating zones is annular space. Increase in Rayleigh number increases the thermal buoyancy strength, accordingly, the instability of flow patterns is seen to be increased with increasing $R a$. Also, the recirculation zone centre shifts upwardly with increasing $R a$ and new small zones form in the lower part of annular space. For 
H. Laidoudi, M. Helmaoui/ Journal of Naval Architecture and Marine Engineering, 17(2020) 89-99

all values of aspect ratio, the effect of inclination angle on streamline depends significantly on value of Rayleigh number. For example, when $R a=10^{3}$ the contours showed that as we move from $\theta=0^{\circ}$ to $\theta=15^{\circ}$, the left recirculation zone is divided into two zones, whereas the right one is kept simple. For the case of $\theta=45^{\circ}$ and $75^{\circ}$ the centre of left zone shifts downwardly, whereas the right zone is still in top part. On other hand, the effect of inclination angle on streamlines for $R a=10^{5}$ is different; the left zone is almost one for all values of inclination angle, while, the right zone develops a small zone for $\theta=45^{\circ}$ and $75^{\circ}$. On the whole, for all values of $R a$ and $E$, it can be concluded that the flow is more stable for the inclination angle $\theta=90^{\circ}$ and the structure of flow patterns of this angle gives an opportunity to the flow velocity to become more important.

Figure 5 shows the effect of Prandtl number and Rayleigh number on streamlines for the aspect ratio $E=0.1$ and 0.5 at fixed inclination angle $\theta=90^{\circ}$. For both values of aspect ratio, it is observed that the effect of Rayleigh on general structure of streamline is more effectible for small value of Prandlt number. It can be concluded that increase in Prandtl number increases the stability of flow patterns inside a cylindrical annulus. This behavior can be explained by the fact that as Prandt number increases from 0.71 to 7.01 the thermal diffusivity of the fluid decreases but the kinematic viscosity increases. The viscosity is always the main factor that increases the stability of fluid flow and it is the principal dissipative agent that converts the kinematic energy into heat.
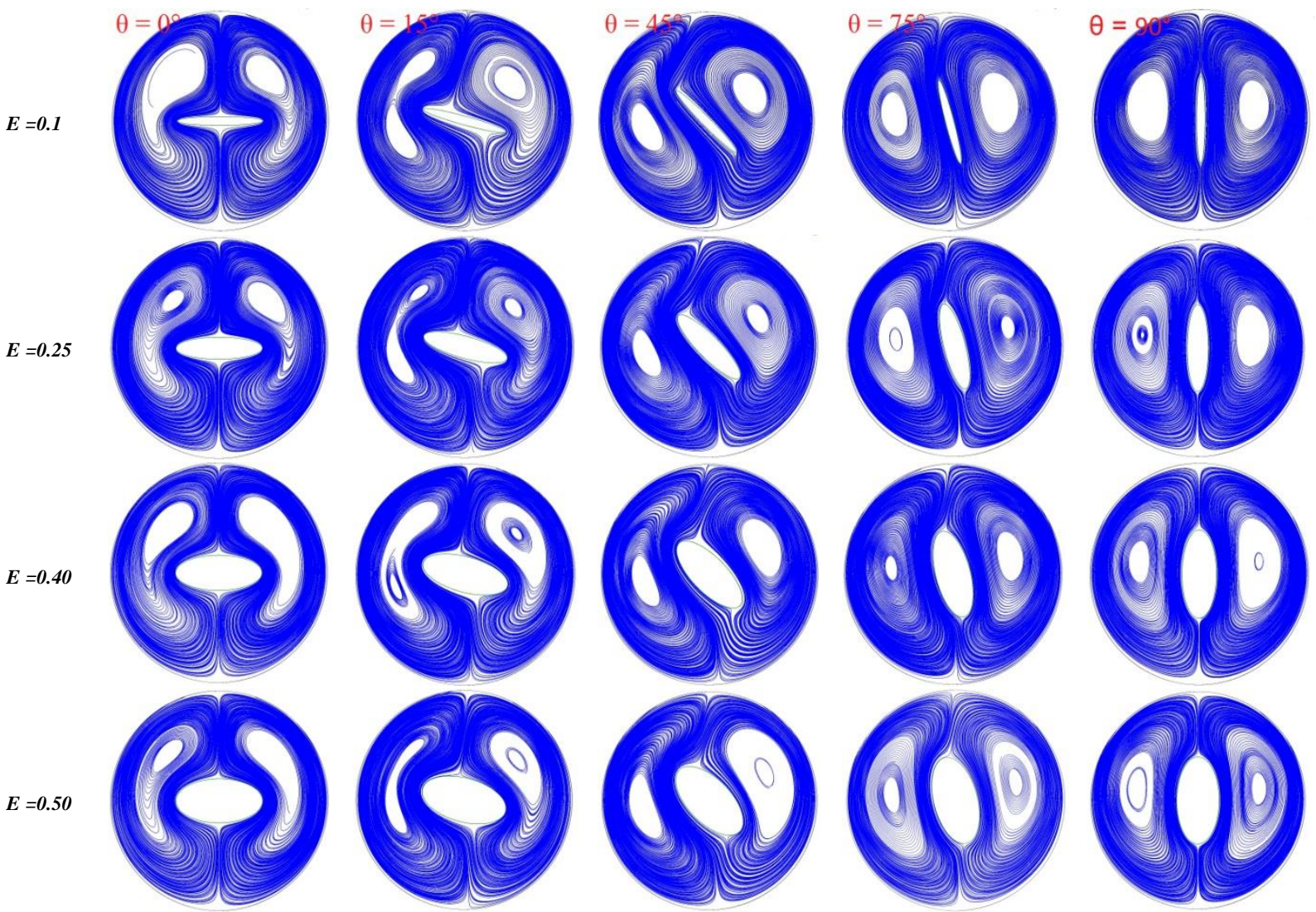

Figure 3: Streamlines for different values of aspect ratio, $E$ and inclination angle at fixed $\operatorname{Pr}=0.71$ and $R a=10^{3}$ 


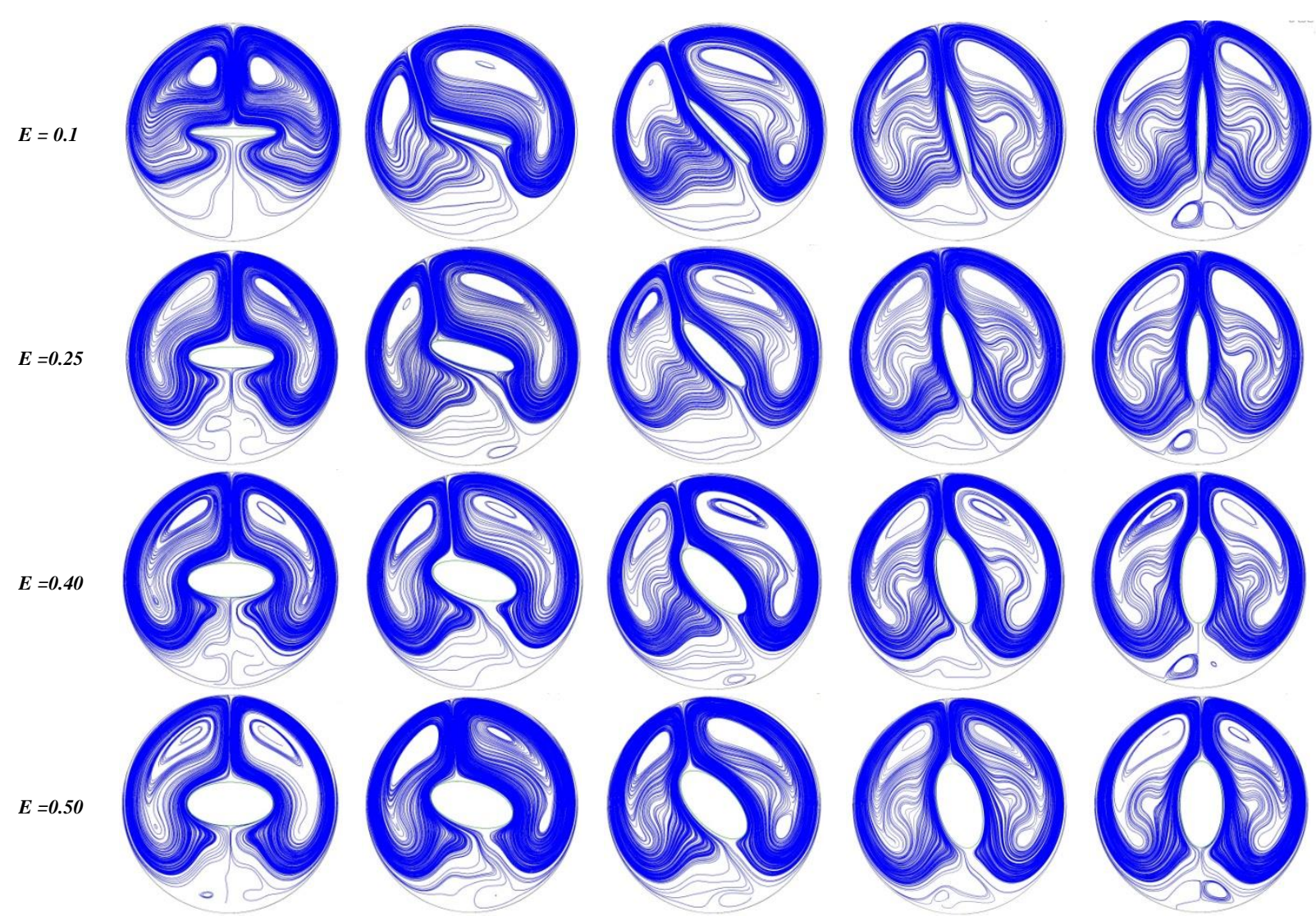

Figure 4: streamlines for different values of aspect ratio, $E$ and inclination angle at fixed $\operatorname{Pr}=0.71$ and $R a=10^{5}$

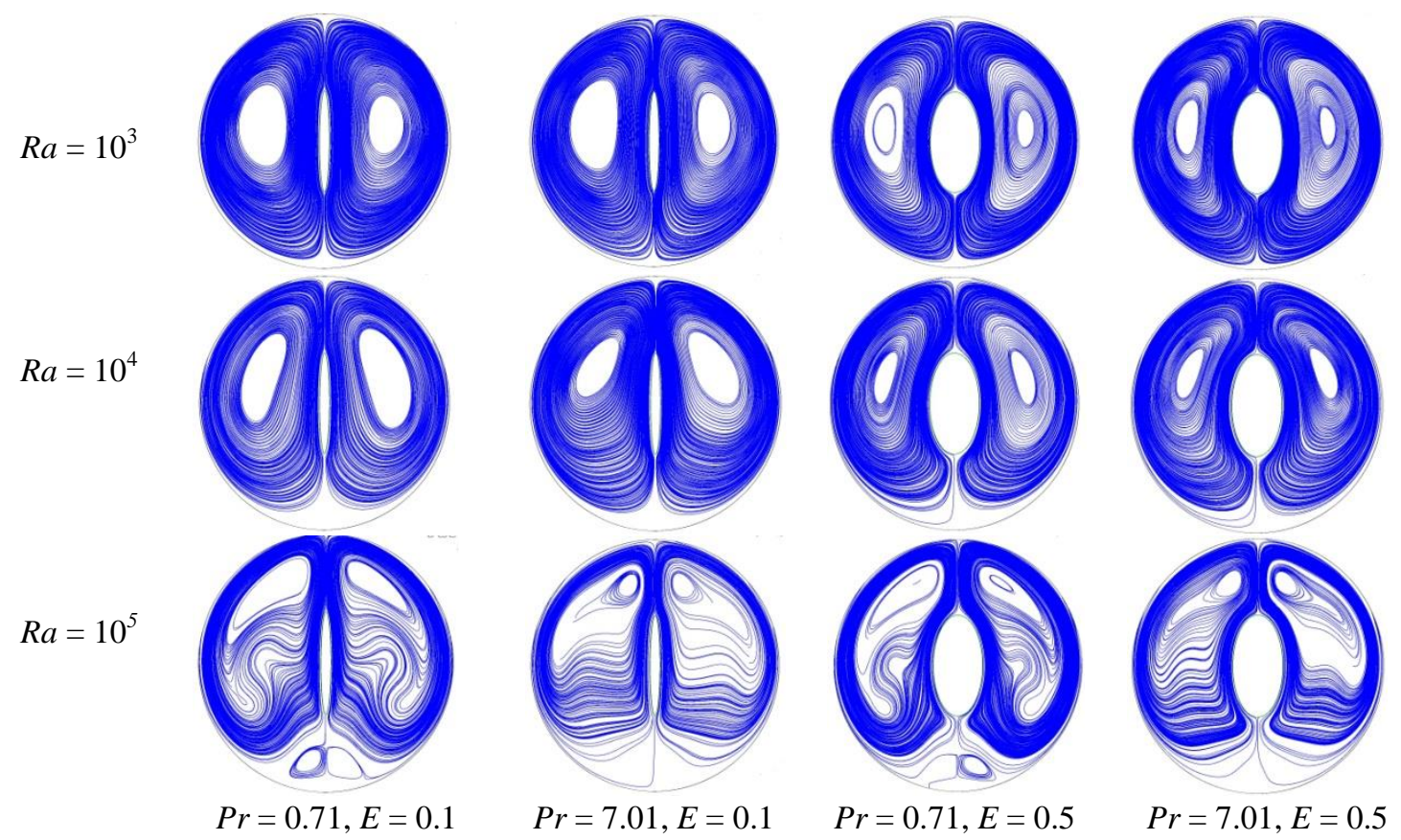

Figure 5: Streamline for aspect ratio $(E=0.1$ and 0.5$), P r=0.71,7.01$ and for different $R a$ 


\subsection{Isotherm contours}

Figure 6 illustrates the preventative isotherm contours in annular space with different values of aspect ratio and inclination angle at fixed $\operatorname{Pr}=0.71$ and $R a=10^{5}$. As the streamlines, the isotherms are seen to be symmetrical for the symmetrical geometries $\left(\theta=0^{\circ}\right.$ and $\left.90^{\circ}\right)$. The isotherms have a diffusion-type like plumes on the upper part of the inner cylinder. This is due to thermal buoyancy that pushes up the hot fluid particles. The plumes shift towards the left direction with increasing the inclination angle from $0^{\circ}$ to $75^{\circ}$. The isotherms are more crowded on the lower surface of inner cylinder indicating the importance of temperature gradient in this zone. Consequently, higher heat transfer rate. Also, it can be observed that for all values of aspect ratio increase in the value of inclination angle increases the temperature gradient around the inner cylinder which hints that increasing the inclination angle enhances the heat transfer rate.

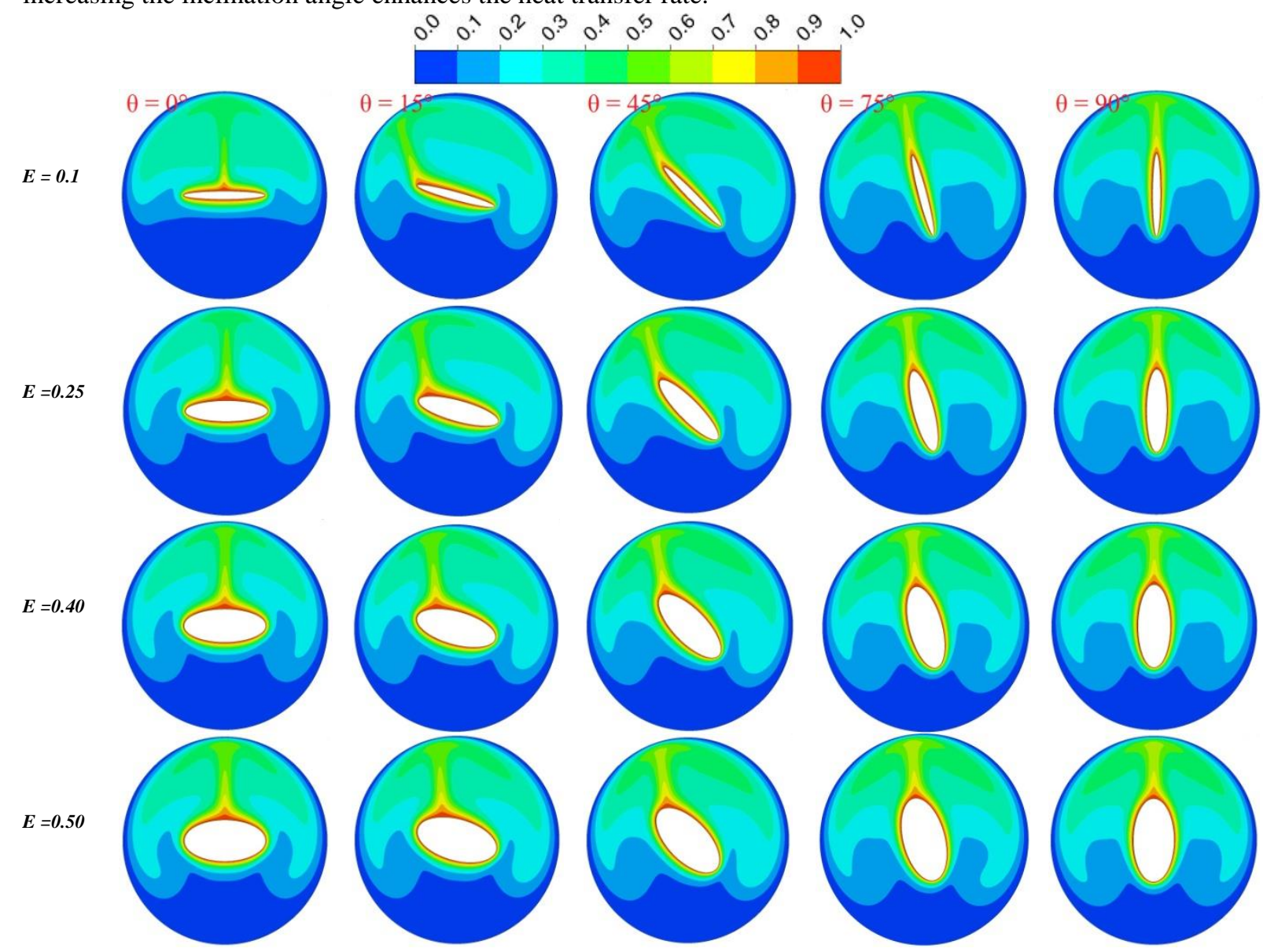

Figure 6: Isotherms for different values of aspect ratio, $E$ and inclination angle at fixed $\operatorname{Pr}=0.71$ and $R a=10^{5}$

Figure 7 shows the effects of Rayleigh number and Prandtl number on isotherms for aspect ratio $E=0.1$ and 0.5 at fixed $\theta=90^{\circ}$. It can be observed that the isotherms become more crowded around the inner cylinder with gradual increase in the value of $R a$ and/or $P r$. This fact predicts that the heat transfer rate increases with $R a$ and/or $P r$.

\subsection{Average Nusselt number}

Figure 8 represents the average Nusselt number of inner cylinder versus the inclination angle for different values of aspect ratio, Prandtl number and Rayleigh number. First of all, the increment of average Nusselt number means the enhancement of heat transfer rate. As it was expected from analyze of streamlines and isotherms. Increase in inclination angle increases the average Nusselt number. Also, increase in Rayleigh number and/or Prandtl number increases the value of Nusselt number. Interesting variation of average Nusselt number is seen for decreasing the value of aspect ratio at the inclination angle $90^{\circ}$. Decrease in aspect ratio increases the average Nusselt number. 


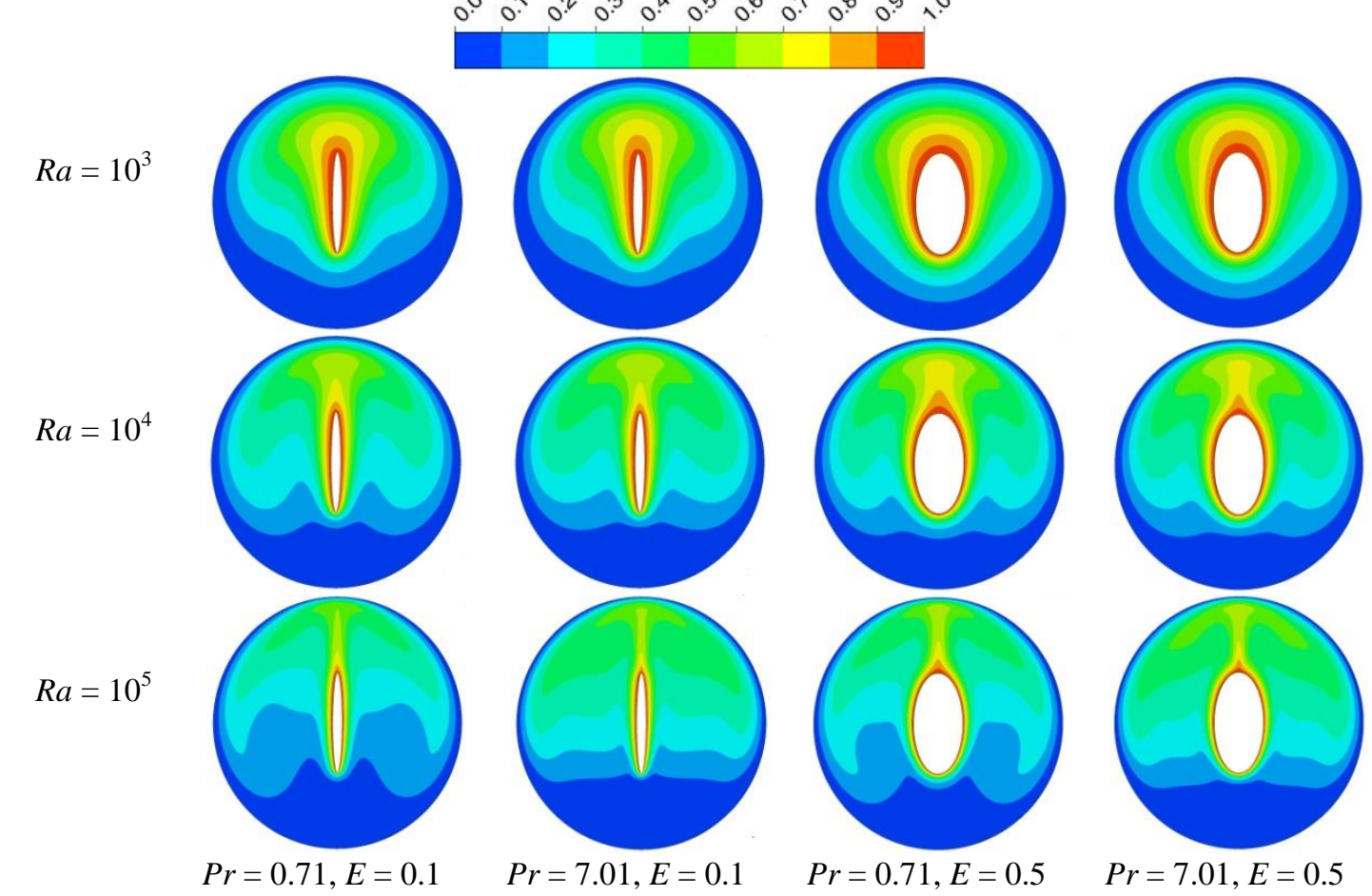

Figure 7: Isotherms for aspect ratio ( $E=0.1$ and 0.5$), P r=0.71,7.01$ and for different $R a$.
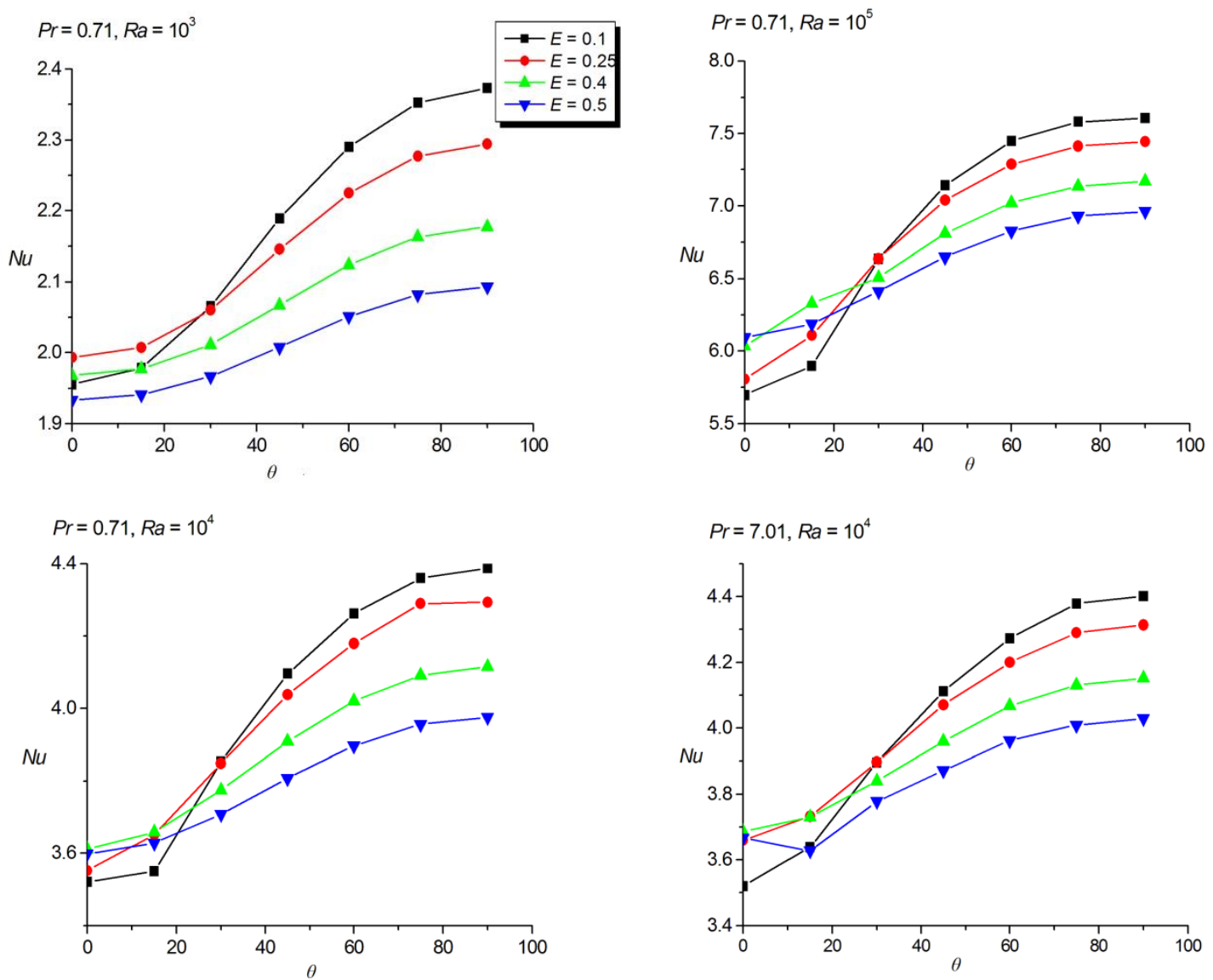

Figure 8a: Variation of mean average Nusselt number versus inclination angle for different values of Ra, Pr and E 

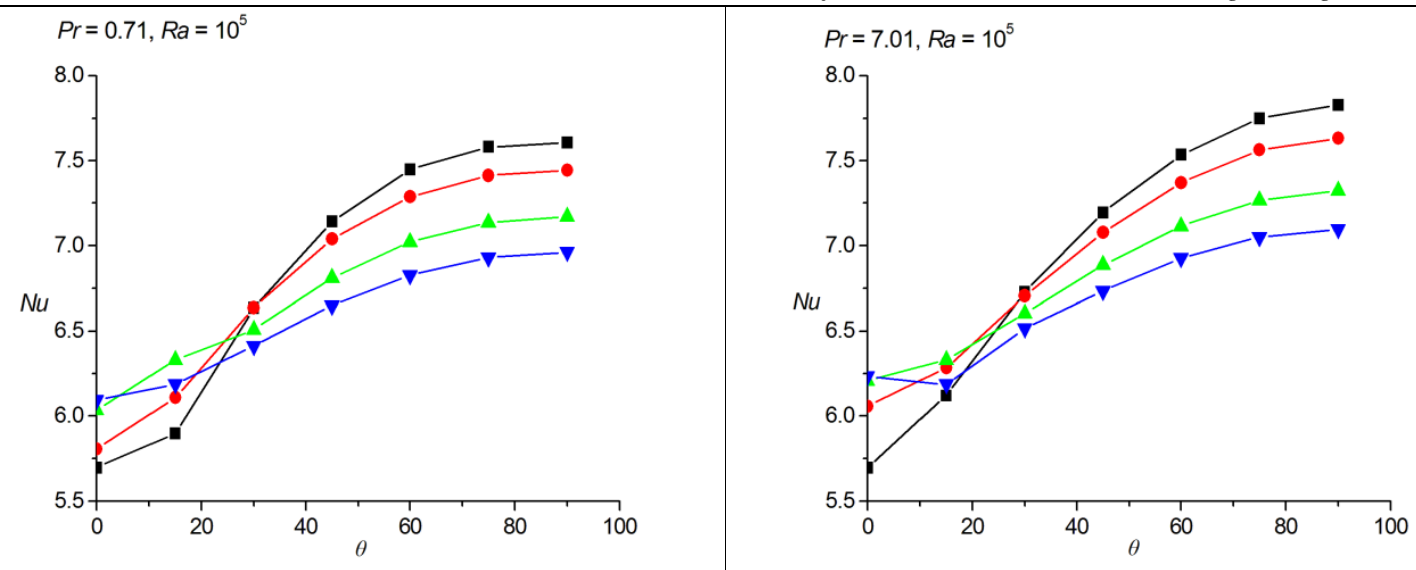

Figure 8b: Variation of mean average Nusselt number versus inclination angle for different values of Ra, $\operatorname{Pr}$ and $\mathrm{E}$

\section{Conclusions}

The laminar natural convection heat transfer between two horizontal cylinders is investigated in this paper. The inner cylinder is elliptical cross-section with different aspect ratio and it is subjected to an inclination angle. The outer cylinder is kept circular. The effects of governing parameters as Rayleigh and Prandtl numbers and the geometrical characteristics as aspect ratio and inclination angle on streamlines and isotherms are presented and discussed. Also the average Nusselt number of inner cylinder is plotted as function of previous governing parameters. The obtained results showed that:

- For the inclination angle $\left(\theta=90^{\circ}\right)$, there is a possibility to reduce the size of inner cylinder while increasing its heat transfer rate.

- The flow patterns is more stable for the inclination angle $\left(\theta=90^{\circ}\right)$.

- Increase in Prandtl number decreases the instability of fluid flow.

- Increasing in the value of Rayleigh number and/or Prandt number increases the heat transfer for all geometrical configurations.

- For $\theta=0^{\circ}$, this geometry is optimal for the insulating applications. The geometry that has $\theta=90^{\circ}$ is optimal for cooling applications as heat exchangers.

\section{References}

Abu-Nada, E., Masoud, Z. and Hijazi, A. (2008): Natural convection heat transfer enhancement in horizontal concentric annuli using nanofluids. International Communications in Heat and Mass Transfer, 35, 657-665.

http://dx.doi.org/10.1016/j.icheatmasstransfer.2007.11.004

Ahmed, K. F. U., Nasrin, R. and Elias, M. (2018): Natural convective flow in circular and ARC-cavities filled with water-cu nanofluid: A comparative study. Journal of Naval Architecture and Marine Engineering, 15, 3752. http://dx.doi.org/10.3329/jname.v15i2.33549

Arbaban, M. and Salimpour, M.R. (2015): Enhancement of laminar natural convective heat transfer in concentric annuli with radial fins using nanofluids. Heat Mass Transfer, 51(3), 353-362.

http://dx.doi.org/10.1007/s00231-014-1380-7

Char, M.I. and Lee, G.C. (1998): Maximum density effects on natural convection of micropolar fluids between horizontal eccentric cylinders. Intentional Journal Engineering Science, 36(2), 157-169.

https://doi.org/10.1016/S0020-7225(97)00023-2

Choi, M.Y. and Choi H.G. (2017): A numerical study on the conjugate natural convection in a circular pipe containing water. Journal of Mechanical Science and Technology, 31 (7), 3261-3269.

https://doi.org/10.1007/s12206-017-0617-z

Eldesouki I.E. (2011): Experimental study of free convection in an elliptical annular enclosure in blunt and slender orientations. Heat Mass Transfer, 47, 81-91. https://doi.org/10.1007/s00231-010-0678-3

Kefayati, GH.R. and Tang, H. (2018): Lattice Boltzmann simulation of viscoplastic fluids on natural convection in an inclined enclosure with inner cold circular/elliptical cylinders (Part I: One cylinder). International Journal of Heat and Mass Transfer, 123, 1138-1162. https://doi.org/10.1016/j.ijheatmasstransfer.2018.01.139

Kuehn T.H. and Goldstein, R. J. (1976): An experimental and theoretical study of natural convection in the annulus between horizontal concentric cylinders. Journal Fluid Mechanics, 74 (4), 695-719.

https://doi.org/10.1017/S0022112076002012 
Kumar, R. (1988): Study of natural convection in horizontal annuli. International Journal of Heat and Mass Transfer, 31 (6), 1137-1148. https://doi.org/10.1016/0017-9310(88)90056-7

Laidoudi, H. (2020a): Buoyancy-driven flow in annular space from two circular cylinders in tandem arrangement. Metallurgical and Materials Engineering, 26 (1), 87-102. https://doi.org/10.30544/481

Laidoudi, H. (2020b): Natural convection from four circular cylinders in across arrangement within horizontal annular space. Acta Mechanica et Automatica, 14 (2), 98-102. https://doi.org/10.2478/ama-2020-0014

Laidoudi, H. (2020c): The role of concave walls of inner cylinder on natural convection in annular space, Acta Mechanica Malaysia, 3(2), 24-28. http://doi.org/10.26480/amm.02.2020.24.28

Laidoudi, H., Ameur, H. (2020) Investigation of the mixed convection of power-law fluids between two horizontal concentric cylinders: Effect of various operating conditions. Thermal Science and Engineering Progress, 20, 100731. https://doi.org/10.1016/j.tsep.2020.100731

Laidoudi, H., Helmaoui, M., Bouzit, M. and Ghenaim, A. (2020): Natural convection of Newtonian fluids between two concentric cylinders of a special cross-sectional form. Thermal Science, OnLine-First Issue 00, 190-190. https://doi.org/10.2298/TSCI200201190L

Lamacz, A., Passerini, A. and Thäter, G. (2011): Natural convection in horizontal annuli: evaluation of the error for two approximations. International Journal on Geomathematics, 2, 307-323.

https://doi.org/10.1007/s13137-011-0023-0

Matin, M. H. and Khan, W. A. (2013): Laminar natural convection of non-Newtonian power-law fluids between concentric circular cylinders, International Communications in Heat and Mass Transfer, 43, 112-121.

http://dx.doi.org/10.1016/j.icheatmasstransfer.2013.02.006

Mebarek-Oudina, F. (2017): Numerical modeling of the hydrodynamic stability in vertical annulus with heat source of different lengths. Engineering Science and Technology, 20(4), 1324-1333.

https://doi.org/10.1016/j.jestch.2017.08.003

Mebarek-Oudina, F. (2018): Convective heat transfer of Titania nanofluids of different base fluids in cylindrical annulus with discrete heat source. Heat Transfer, 48(1), 135-147. https://doi.org/10.1002/htj.21375

Mebarek-Oudina, F. and Bessaih R.(2019): Numerical simulation of natural convection heat transfer of copperwater nanofluid in a vertical cylindrical annulus with heat sources, 26(3), 325-334.

https://doi.org/10.1134/S0869864319030028

Nada, S.A. and Said M.A. (2019): Effects of fins geometries, arrangements, dimensions and numbers on natural convection heat transfer characteristics in finned-horizontal annulus, International Journal of Thermal Sciences, 137, 121-137. https://doi.org/10.1016/j.ijthermalsci.2018.11.026

Nasiri, D. Dehghan, A. A. and Hadian, M. R. (2017): Conjugate natural convection between horizontal eccentric cylinders. Heat Mass Transfer, 53 (3), 799-811. https://doi.org/10.1007/s00231-016-1862-X

Sheremet, M.A., and Pop, I. (2015): Natural convection in a horizontal cylindrical annulus filled with a porous medium saturated by a nanofluid using Tiwari and Das' nanofluid model. European Physical Journal Plus, 130, 107, 1-12. https://doi.org/10.1140/epjp/i2015-15107-4

Tayebi, T., Chamkha, A. J. , Djezzar, M. and Bouzerzour, A.( 2017) : Natural convective nanofluid flow in an annular space between confocal elliptic cylinders. Journal of Thermal Science and Engineering Applications, 9(1), 011010. https://doi.org/10.1115/1.4034599

Wei, J.G. and Tao, W.Q. (1996): Three-dimensional numerical simulation of natural convection heat transfer in an inclined cylindrical annulus. Journal of Thermal Science, 5 (3), 175 - 183.

https://doi.org/10.1007/BF02653182

Yoo, J.S. and Han, S.M. (2000): Transitions and chaos in natural convection of a fluid with $\operatorname{Pr}=0.1$ in a horizontal annulus. Fluid Dynamics Research, 27, 231-245. https://doi.org/10.1016/S0169-5983(00)00004-6

Zhang, H.L., Tao, W.Q. and Wu, Q.J. (1992): Numerical simulation of natural convection in circular enclosures with inner polygonal cylinders, with confirmation by Experimental Results. Journal of Thermal Science, 1 (4), 249 - 258. https://doi.org/10.1007/BF02653204 